\title{
Multifunctional properties of ceria nanocubes synthesized by a hydrothermal method
}

\author{
R V LAKSHMI ${ }^{1}$, KAMALESH PAL ${ }^{2}$, TAPAS KUMAR MANDAL ${ }^{3}$ and S T ARUNA ${ }^{1, * \mathbb{D}}$ \\ ${ }^{1}$ Surface Engineering Division, CSIR-National Aerospace Laboratories, Bengaluru 560017, India \\ ${ }^{2}$ Department of Chemistry, Jadavpur University, Kolkata 700032, India \\ ${ }^{3}$ Department of Chemistry, Indian Institute of Technology Roorkee, Roorkee 247667, India \\ *Author for correspondence (aruna_reddy@ nal.res.in)
}

MS received 3 September 2018; accepted 2 February 2019

\begin{abstract}
Nanosized ceria is an extremely versatile and commercially valuable material because of its industrially important applications. The present work describes the synthesis of ceria nanocubes by a simple hydrothermal method. The size of the synthesized ceria nanocubes are 8-20 nm. The formation of ceria phase has been corroborated by X-ray photoelectron spectroscopy and X-ray diffractometry. Selected area electron diffraction patterns obtained for the nanocubes are also precisely indexed to the cubic ceria phase. The synthesized ceria nanocubes exhibit a high surface area of $26 \mathrm{~m}^{2} \mathrm{~g}^{-1}$ and also high catalytic activity. The work also investigates the influence of ceria nanocubes on the corrosion resistance of sol-gel hybrid coatings in $3.5 \% \mathrm{NaCl}$ solution on AA2024 substrates. The corrosion behaviour of the sol-gel coatings revealed that ceria nanocubes reinforce the barrier properties of the sol-gel coatings and confer longer active protection to the metallic substrate.
\end{abstract}

Keywords. Oxides; synthesis; sol-gel; photoelectron spectroscopy; catalytic properties; corrosion resistance.

\section{Introduction}

Cerium oxides (ceria, $\mathrm{CeO}_{2-\delta}$, where $\delta=0-0.5$ ) have gained a lot of research interest for various applications due to their unique properties. Cerium oxide-based materials have been extensively investigated and widely used in various applications, such as oxygen storage, catalysts, gas sensors, UV blockers, electronics and corrosion resistance, and the functional layer is made up of solid oxide fuel cells [1-17]. Cerium oxides have been one of the most widely used heterogeneous catalysts for several technologically important reactions $[2-4,18-20]$. Their catalytic traits can be attributed to two of their main properties, namely oxygen storage capacity of ceria due to the propensity of $\mathrm{Ce}$ to change between $\mathrm{Ce}^{3+}$ and $\mathrm{Ce}^{4+}$ and high mobility [21]. Also, Ce is widely abundant in the earth's crust (64 ppm); it is inexpensive and an effective substitute for noble metal catalysts [22,23].

In recent years, there has been increased interest in the synthesis and application of nano-dimensional materials as they exhibit unique size and shape-dependent physical and chemical properties compared to bulk materials. They exhibit a higher surface area to volume ratio along with quantum confinement and can also be self-assembled for device applications. Within this context, nano- $\mathrm{CeO}_{2}$ is a unique, versatile and useful material and its properties vary dramatically from the bulk material [24-27]. The properties of nano- $\mathrm{CeO}_{2}$ can be tuned by the choice of the preparation method, particle shape, particle size, nature of dopant and surface chemistry. Therefore, the preparation method of nano- $\mathrm{CeO}_{2}$ is one of the important factors to obtain $\mathrm{CeO}_{2}$ for desired applications.

Nanosized cerium oxide particles with tailored size and properties can be synthesized by numerous techniques. In recent years, wet chemical methods have been comprehensively investigated, altered and refined to find cost-effective and environmental friendly pathways for the fabrication of desired metal oxide nanostructures [28]. For the industrial scale production of cerium nanosized oxides, the homogeneous precipitation method is being used. The hydrothermal method is the only process which yields nanosized cerium oxides in different shapes like wires, tubes and polyhedra [2931]. Pahari et al [32] have synthesized monodispersed ceria nanocubes under hydrothermal conditions using decanoic acid. Mai et al [1] have also synthesized ceria nanocubes using $\mathrm{NaOH}$ and studied their oxygen storage capacity. The use of $\mathrm{CeO}_{2}$ nanoparticles as corrosion inhibitors for aluminium alloys has been recently investigated to avoid the loss or adverse effects of the inhibitor when it has been used in the form of dissolved salts $[33,34]$. However, the application of ceria nanocubes for corrosion protection is seldom reported. 
Further, $\mathrm{CO}$ oxidation by $\mathrm{O}_{2}$ is one of the important reactions in exhaust catalysis, which is particularly involved in the primary function of three-way catalytic converters, diesel oxidation catalysts and diesel particulate filters. It is a very simple and ideal reaction in heterogeneous catalysis and has been used as a model reaction for probing the oxidation activity of several catalysts. $\mathrm{CO}$ oxidation has been carried out over different types of $\mathrm{CeO}_{2}$-based oxide catalysts [3,4].

Herein, we report a very simple and facile method for the preparation of ceria nanocubes using Triton X-100 as the surfactant. Surfactants have proven to be the best shape directing agents in the synthesis of nanomaterials, which is primarily related to the surface adsorption of surface active molecules on different crystal planes of nucleating centres, thus controlling their overall shape. UV-Vis absorption properties, thermal stability, corrosion inhibiting ability and catalytic properties of the synthesized $\mathrm{CeO}_{2}$ nanocubes are studied. In addition, investigation of the oxidation state of $\mathrm{Ce}$ ions and their estimation in $\mathrm{CeO}_{2}$ nanocubes are carried out using $\mathrm{X}$ ray photoelectron spectroscopy (XPS). The results regarding the corrosion and catalytic properties obtained are compared with the reported data and are found to exhibit improved properties.

\section{Experimental}

\subsection{Materials}

Cerium nitrate hexahydrate (Merck) was used as the source for cerium and ethanol (Merck) was used as the solvent medium. Ammonia solution (25\%) was obtained from Loba Chemie. Triton X-100 was procured from Fluka. All chemical reagents were of analytical grade and were used without any further purification. Milli-Q water was used for the synthesis.

3-glycidoxypropyltrimethoxysilane (GPTMS), aluminiumtri-sec-butoxide (ASB) and ethylacetoacetate were procured from Sigma-Aldrich and were used for the synthesis of sol and a $1.2 \mathrm{~mm}$ thick AA2024-T3 (Alcoa) aluminium alloy sheet was used as the substrate.

\subsection{Preparation}

Ceria nanocubes were prepared using cerium nitrate and ammonia with Triton X-100 as the surfactant. Triton X-100, a nonionic surfactant, helps in providing colloidal stability and in achieving controlled nucleation and has been used for the first time in the synthesis of ceria nanocubes. Briefly, $0.2 \mathrm{~g}$ Triton X-100 was taken in about $60 \mathrm{ml}$ water and $0.8 \mathrm{~g}$ cerium nitrate was added to it. The mixture was slowly stirred till they completely dissolved and formed a clear solution. To this, $8 \mathrm{ml}$ of ammonia solution was slowly added while stirring which resulted in an off-white precipitate. The entire mixture was transferred to a Teflon container and was autoclaved at $150^{\circ} \mathrm{C}$ for $3 \mathrm{~h}$. The ceria particles synthesized after extraction were stored as a suspension in ethanol and processed suitably for further characterization.

The synthesized $\mathrm{CeO}_{2}$ nanocubes have also been tested for corrosion inhibition properties of AA2024-T3 substrates using a hybrid sol reported elsewhere [35]. Briefly, the sol was synthesized from GPTMS and ASB (mole ratio of 2:1). The silica-alumina organic-inorganic hybrid sol was prepared by hydrolysing the precursors separately under acidic conditions $\left(0.2 \mathrm{M} \mathrm{HNO}_{3}\right)$ followed by stirring for $120 \mathrm{~min}$.

\subsection{Characterization}

The ceria particles were characterized using a field emission scanning electron microscope (FESEM) (Model Carl Zeiss Supra VP40) equipped with an energy dispersive X-ray spectrometer (Oxford Instruments). The particles were also analysed using a high-resolution transmission electron microscope (HRTEM) (JEOL-JEM 2100F). The phase purity of the as-synthesized cerium oxide nanoparticles was confirmed by X-ray diffractometry (XRD, Bruker D8 advance). XPS data of $\mathrm{CeO}_{2}$ nanocubes were recorded (SPECS spectrometer). A non-monochromatic AlK $\alpha$ radiation $(1486.6 \mathrm{eV}$ ) was used as the X-ray source and was operated at $150 \mathrm{~W}$. A Ce3d core level spectrum was obtained with a pass energy of $25 \mathrm{eV}$ at a step increment of $0.05 \mathrm{eV}$. The binding energies were referenced with the $\mathrm{C} 1 \mathrm{~s}$ peak at $284.6 \mathrm{eV}$. The curves were fitted with a Casa XPS program. The Ce3d core level spectrum was subjected to Shirley background subtraction and fitted into several components with Gaussian-Lorentzian peaks and, by slightly varying the peak positions, spin-orbit splitting, doublet intensity ratios and full width at half maximum as followed in the literature [36]. $\mathrm{CeO}_{2}$ nanocubes were characterized by UV-Vis diffuse reflectance spectroscopy (UV-Vis DRS, Shimadzu UV-2450 UV-Vis spectrophotometer) in the wavelength range of 200-800 nm using $\mathrm{BaSO}_{4}$ as the reference material. The Kubelka-Munk (K-M) function was used for converting the reflectance data to absorbance terms [37]:

$$
F\left(R_{\infty}\right)=\left(1-R_{\infty}\right)^{2} / 2 R_{\infty}
$$

where $R_{\infty}$ is the reflectance of the sample and $F\left(R_{\infty}\right)$ is the $\mathrm{K}-\mathrm{M}$ function. The band gap energies were estimated with the help of a Tauc plot and considering a direct band gap transition for $\mathrm{CeO}_{2}$ using the following expression [38]:

$$
(\alpha h v)^{2}=A\left(h v-E_{\mathrm{g}}\right)
$$

where $E_{\mathrm{g}}, A, \alpha$ and $h v$ are the band gap, proportionality constant, absorption coefficient and incident light energy, respectively.

The thermal stability of the synthesized particles was studied by differential scanning calorimetry (DSC) and thermo gravimetric analysis (TGA). DSC curves were obtained from a Perkin Elmer DSC, model Diamond DSC. TGA data were obtained from a Perkin Elmer Pyris 1 TGA. 


\subsection{Corrosion inhibition properties}

The corrosion inhibition properties of the $\mathrm{CeO}_{2}$ nanocubes were examined by electrochemical impedance spectroscopy (EIS) using an electrochemical workstation (CHI604D) and a conventional three electrode cell in $3.5 \mathrm{wt} \%(0.6 \mathrm{M}) \mathrm{NaCl}$ solution. A coated sample with an active area of $1 \mathrm{~cm}^{2}$ was used as the working electrode; a platinum foil and standard calomel electrode were used as the counter electrode and reference electrode, respectively. Upon establishment of the open circuit potential, measurements were carried out over a frequency range of $100 \mathrm{kHz}-0.01 \mathrm{~Hz}$ by applying a sinusoidal wave with an amplitude of $10 \mathrm{mV}$.

\subsection{Catalytic properties}

To study the $\mathrm{CO}$ oxidation activity of the synthesized mate-

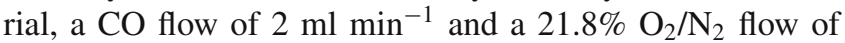
$10 \mathrm{ml} \mathrm{min}{ }^{-1}$ balanced with $\mathrm{N}_{2}$ (total flow $=110 \mathrm{ml} \mathrm{min}^{-1}$ with a $\mathrm{CO} / \mathrm{O}_{2}$ mole ratio of 1) are used to maintain a gas hourly space velocity of $120,000 \mathrm{~h}^{-1}$. The reaction compositions were analysed by an online gas chromatograph (GC) (Agilent 7890A GC). The GC was equipped with columns of polar Porapak $\mathrm{Q}$ and molecular sieves of $5 \AA$ columns, a thermal conductivity detector (TCD) and a flame ionization detector (FID). All permanent gases were separated by molecular sieves and all other components were separated by a polar-packed column. The GC was calibrated using known flow rates of pure gases, such as $\mathrm{CO}, \mathrm{CO}_{2}$ and $\mathrm{H}_{2}$ and $\mathrm{CH}_{4}$ with $\mathrm{N}_{2}$ as the internal standard. Ultra-high purity gases (purity $>$ 99.99\%, CHEMIX Specialty Gases and Equipment) were used. The TCD was used for monitoring the effluent concentrations of all components. The FID associated with a methanizer was used to increase the sensitivity towards $\mathrm{CO}$ and $\mathrm{CO}_{2}$.

The CO conversion $\left(X_{\mathrm{CO}}\right)$ has been defined by the following equation:

$$
X_{\mathrm{CO}}=\frac{[\mathrm{CO}]_{\text {in }}-[\mathrm{CO}]_{\text {out }}}{[\mathrm{CO}]_{\text {in }}} \times 100,
$$

where $[\mathrm{CO}]_{\text {in }}$ and $[\mathrm{CO}]_{\text {out }}$ are the inlet and outlet molar concentrations of $\mathrm{CO}$, respectively. Approximately after $30 \mathrm{~min}$ reaction, once steady state was reached at a particular temperature, the gas sample from the reactor was analysed. At each temperature, three gas samples were analysed and the last GC data were used as the steady state value. Details of experiments are described in detail elsewhere [39].

\section{Results and discussion}

\subsection{Morphological characteristics}

The as-prepared $\mathrm{CeO}_{2}$ nanocubes were dispersed in ethanol by ultrasonication and were characterized by FESEM and transmission electron microscopy (TEM) to determine their shape and size. Figure 1a shows the FESEM images of the asprepared ceria nanocubes. The image shows the formation of a well-defined cubic morphology of ceria present as aggregates. The size of the nanocubes appeared to be in the range from 8 to $20 \mathrm{~nm}$. To have a better clarity on the size, TEM images have been recorded and are shown in figure $1 \mathrm{~b}$. The size of the nanoparticles is very clear from the TEM images. The HRTEM image of the as-prepared $\mathrm{CeO}_{2}$ nanocubes is shown as an inset. The lattice spacing of the parallel fringes corresponding to the (111) plane of the face-centred cubic ceria is $0.31 \mathrm{~nm}$. The selected area electron diffraction (SAED) pattern of the same nanocubes is also shown in figure 1c, which has been taken as one of the particles of the agglomerate. All the rings of the diffracted pattern are precisely indexed to the cubic $\mathrm{CeO}_{2}$ phase.

\subsection{XRD analysis}

Figure 2 shows the XRD pattern of the as-prepared $\mathrm{CeO}_{2}$ nanocubes. The obtained XRD pattern matches well with the standard JCPDS pattern of $\mathrm{CeO}_{2}$ (\#81-0792). All the reflections of the powder pattern obtained represent the cubic fluorite structure of $\mathrm{CeO}_{2}$. The sharp diffraction peaks suggest a high degree of crystallinity in the synthesized $\mathrm{CeO}_{2}$.

\subsection{XPS analysis}

The $\mathrm{Ce} 3 \mathrm{~d}$ core level spectrum of $\mathrm{CeO}_{2}$ nanocubes has been recorded to understand the surface nature of $\mathrm{CeO}_{2}$ nanocubes. It is evident from the nature of the spectral envelope of $\mathrm{Ce} 3 \mathrm{~d}$ that $\mathrm{Ce}$ is present in both the +4 and +3 oxidation states and can be resolved into several $\mathrm{Ce} 3 \mathrm{~d}_{5 / 2,3 / 2}$ spin-orbit doublet peaks. The curve-fitted $\mathrm{Ce} 3 \mathrm{~d}$ core level spectrum of $\mathrm{CeO}_{2}$ nanocubes is shown in figure 3 . The Ce $3 \mathrm{~d}$ spectrum exhibits 10 peaks and each of the 5 doublets are related to $3 \mathrm{~d}_{5 / 2}$ (indicated as $v$ ) and $3 \mathrm{~d}_{3 / 2}$ (indicated as $u$ ) components [12]. There are three doublet peaks. They are indicated as $v-u(882.8$ and $901.1 \mathrm{eV})$, $v^{\prime \prime}-u^{\prime \prime}(889.3$ and $907.2 \mathrm{eV})$ and $v^{\prime \prime \prime}-u^{\prime \prime \prime}$ (898.4 and 916.5 $\mathrm{eV})$ and are assigned to the presence of $\mathrm{Ce}^{4+}$ species. The peaks designated as $v_{\mathrm{o}}-u_{\mathrm{o}}(881.2$ and $899.7 \mathrm{eV})$ and $v^{\prime}-u^{\prime}$ ( 885.5 and $903.1 \mathrm{eV})$ are assigned to $\mathrm{Ce}^{3+}$ species [2] and the $u^{\prime \prime \prime}$ peaks are well separated, which proves that the presence of $\mathrm{Ce}^{4+}$ species in Ce compounds is evident. Spin-orbit peaks corresponding to $v^{\prime \prime \prime}$ and $u^{\prime \prime \prime}$ are observed at 898.0 and $916.6 \mathrm{eV}$ with a separation of $18.6 \mathrm{eV}$ and are associated with primary photoionization from $\mathrm{Ce}^{4+}$ with the $\mathrm{Ce} 3 \mathrm{~d}^{9} 4 \mathrm{f}^{0} \mathrm{O} 2 \mathrm{p}^{6}$ final state. Lower binding energy states of $v^{\prime \prime}-u^{\prime \prime}$ and $v-u$ correspond to the $\mathrm{Ce} 3 \mathrm{~d}^{9} 4 \mathrm{f}^{1} \mathrm{O} 2 \mathrm{p}^{5}$ and $\mathrm{Ce} 3 \mathrm{~d}^{9} 4 \mathrm{f}^{2} \mathrm{O} 2 \mathrm{p}^{4}$ final state shake-down satellite features $[36,40]$. The primary photoionization process facilitated the charge transfer of the ligand $(\mathrm{O} 2 \mathrm{p})$ to metal $(\mathrm{Ce} 4 \mathrm{f})$, resulting in satellite peaks. In $\mathrm{Ce}^{3+}$, the lower binding energy $v_{\mathrm{o}}-u_{\mathrm{o}}$ peaks are assigned to the characteristic $\mathrm{Ce} 3 \mathrm{~d}^{9} 4 \mathrm{f}^{2} \mathrm{O} 2 \mathrm{p}^{5}$ final state shake-down satellites and $v^{\prime}-u^{\prime}$ spin orbit doublet peaks are due to the main photoionization from the $\mathrm{Ce} 3 \mathrm{~d}^{9} 4 \mathrm{f}^{1} \mathrm{O} 2 \mathrm{p}^{6}$ final state $[35,38]$. 

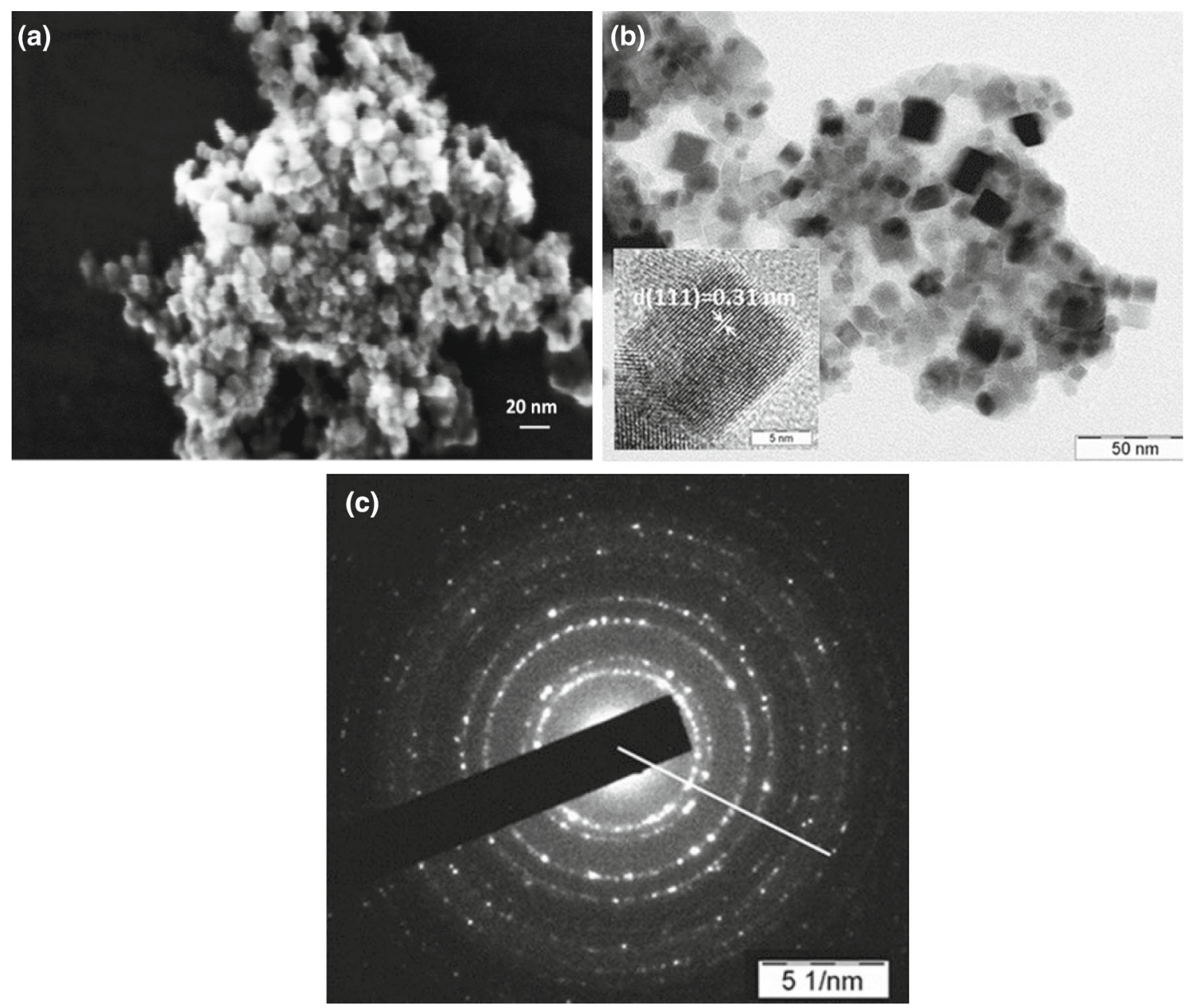

Figure 1. Microscopic images of the as-prepared ceria nanocubes: (a) FESEM, (b) TEM and (c) SAED pattern.

The relative concentrations $(C)$ of $\mathrm{Ce}^{4+}$ and $\mathrm{Ce}^{3+}$ components were estimated from their peak areas $(A)$ using the following equations [36]:

$$
\begin{aligned}
& A_{\mathrm{Ce}^{3+}}=A_{v_{o}}+A_{u_{o}}+A_{v^{\prime}}+A_{u^{\prime}}, \\
& A_{\mathrm{Ce}^{4+}}=A_{v}+A_{u}+A_{v^{\prime \prime}}+A_{u^{\prime \prime}}+A_{v^{\prime \prime \prime}}+A_{u^{\prime \prime \prime}}, \\
& C_{\mathrm{Ce}^{3+}}=\frac{A_{\mathrm{Ce}^{3+}}}{A_{\mathrm{Ce}^{4+}}+A_{\mathrm{Ce}^{3+}}} .
\end{aligned}
$$

The concentration of $\mathrm{Ce}^{3+}$ in the $\mathrm{CeO}_{2}$ nanocube is estimated to be $36 \%$ with respect to the total amount of the Ce species, which indicates that $\mathrm{Ce}$ is mostly present in the +4 oxidation state.

\subsection{UV-Vis absorption analysis}

The optical properties of the ceria nanocubes were studied by UV-Vis DRS. The absorption spectrum in the $\mathrm{K}-\mathrm{M}$ unit shown in figure 4 primarily reveals two-peak features (p1 and p2) in the range of 200-400 nm with an increased absorption at the longer wavelength side. The absorption 'p2' $(\sim 300 \mathrm{~nm})$ is attributed to the $\mathrm{Ce}^{4+}(4 \mathrm{f})$ $\leftarrow \mathrm{O}^{2-}(2 \mathrm{p})$ interband transition in $\mathrm{CeO}_{2}$, while the weaker absorption feature ' $\mathrm{p} 1$ ' $(\sim 240 \mathrm{~nm})$ arises largely due to the $\mathrm{Ce}^{3+}(4 \mathrm{f}) \leftarrow \mathrm{O}^{2-}(2 \mathrm{p})$ transition because of the presence of a low coordinated surface like $\mathrm{Ce}^{3+}$. Furthermore, absorptions around 200-250 nm because of $5 \mathrm{~d}^{1} \leftarrow 4 \mathrm{f}^{1}$ transitions of isolated $\mathrm{Ce}^{3+}$ may also partly cover or overlap with the 'p1' feature [41]. The enhanced 'p2' feature and the relatively weaker ' $\mathrm{p}$ ' feature are consistent with the $\mathrm{Ce}^{3+} / \mathrm{Ce}^{4+}$ contents in the $\mathrm{CeO}_{2}$ nanocubes as reflected in XPS analysis.

Considering the crystallite size of the $\mathrm{CeO}_{2}$ nanocubes (in the range of $8-20 \mathrm{~nm}$ ), band gap moderation due to the quantum confinement effect is not expected to be pronounced [42]. The estimated band gap of $3.51 \mathrm{eV}$ (from a Tauc plot, the inset of figure 4) is found to be higher than that usually observed for bulk $\mathrm{CeO}_{2}$ samples and is due to the direct band gap transition of $\mathrm{CeO}_{2-\delta}$. This increased band gap can be attributed to the presence of oxygen defects in $\mathrm{CeO}_{2-\delta}$ due to the presence of $\mathrm{Ce}^{3+}$ as evidenced by the XPS results. 


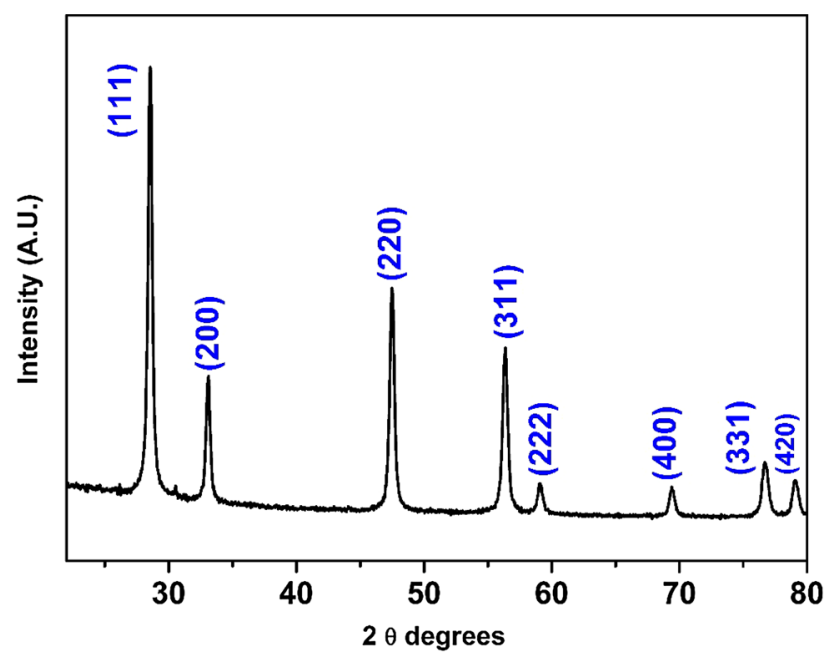

Figure 2. XRD pattern of $\mathrm{CeO}_{2}$ nanocubes.

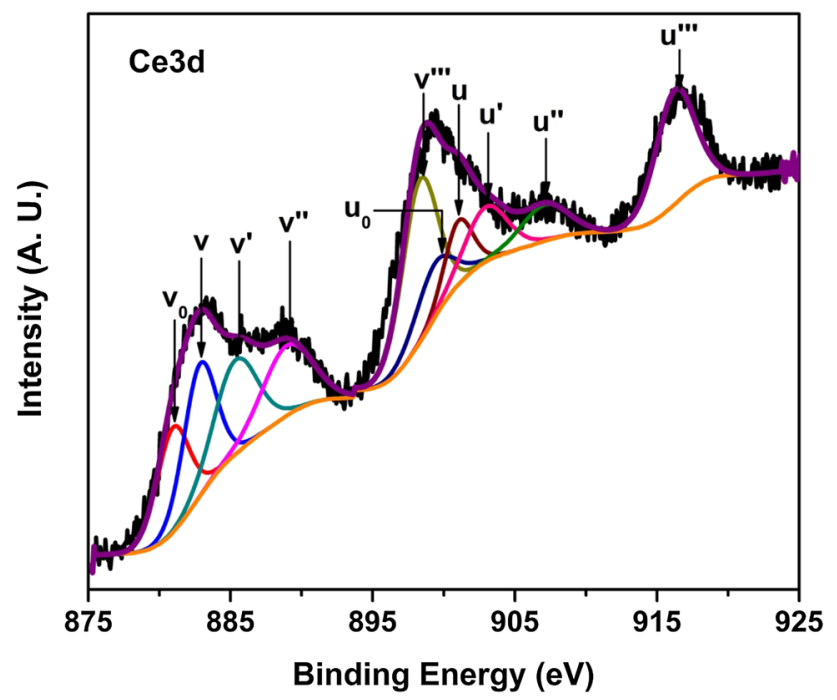

Figure 3. XPS of the $\mathrm{Ce} 3 \mathrm{~d}$ core level of $\mathrm{CeO}_{2}$ nanocubes.

\subsection{Thermal analysis}

Thermal stability and various exothermic and endothermic transitions of the synthesized $\mathrm{CeO}_{2}$ nanocubes have been analysed using TGA and DSC techniques. The TGA-DSC curves of the as-prepared $\mathrm{CeO}_{2}$ nanocubes are shown in supplementary figure $\mathrm{S} 1$. The total weight loss as per the TGA curve is only about $2 \%$, indicating that there is not much hydrated water or unreacted residues left. The DSC curve also shows no major exo- or endo-peaks in the entire temperature range. This indicates that the product had formed completely.

\subsection{Corrosion inhibition properties}

The corrosion inhibiting coatings prepared by dispersing $\mathrm{CeO}_{2}$ nanocubes in the hybrid sol and coating it onto the

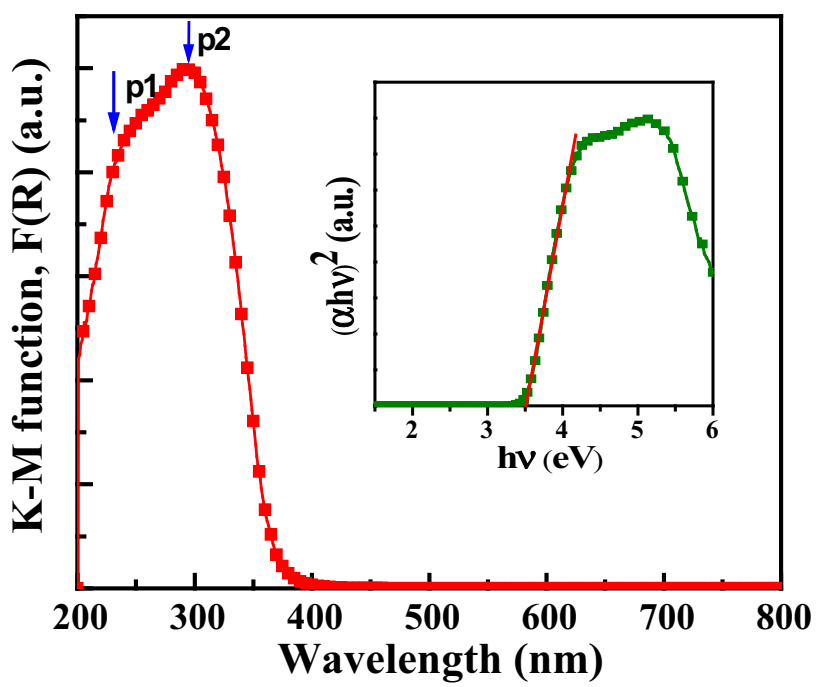

Figure 4. UV-Vis spectrum and a Tauc plot (inset) of $\mathrm{CeO}_{2}$ nanocubes.
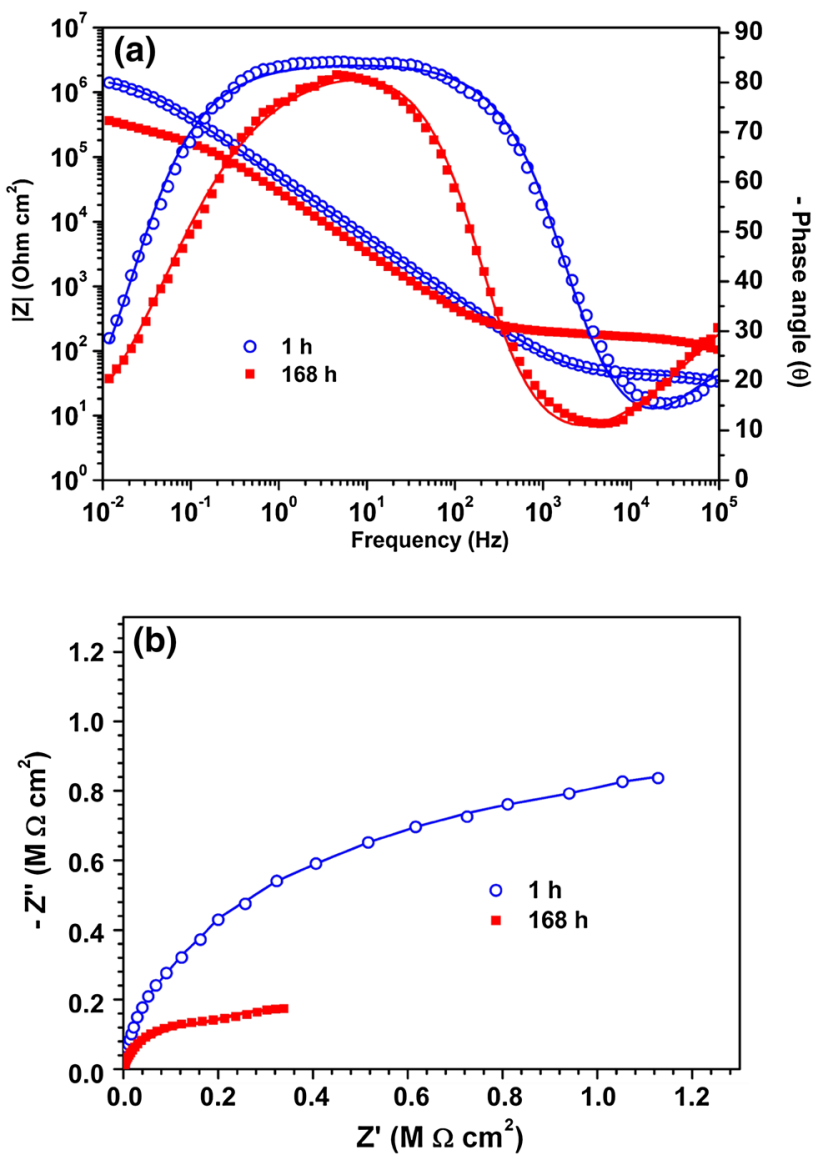

Figure 5. EIS analysis of sol-gel coatings with $\mathrm{CeO}_{2}$ nanocubes under different immersion conditions in $3.5 \% \mathrm{NaCl}$ solution.

substrate were tested for their performance [43]. Their electrochemical behaviour in $3.5 \% \mathrm{NaCl}$ solution was studied using EIS. This technique allows the separation of responses, 
such as capacitance and resistance from the coating and the interfaces. The evolution of these parameters helps in understanding the active and passive corrosion protections offered to the alloy. EIS curves obtained for the coatings with $\mathrm{CeO}_{2}$ nanocubes are presented in figure $5 \mathrm{a}$ and $\mathrm{b}$. The data have been compared with the coating without $\mathrm{CeO}_{2}$ nanocubes to assess the corrosion inhibition properties (supplementary figure S2). The contribution related to the Faradic reactions at the metal surface is often identified from the contour of the acquired impedance spectra in the low frequency region. The impedance modulus values in the low frequency region of the Bode plot are compared to describe the corrosion protection ability of the coating. The higher the value, the better is the protection rendered. Coatings with ceria nanocubes show improvement in the impedance value both under 1 and $168 \mathrm{~h}$ conditions. This implies that the $\mathrm{CeO}_{2}$ nanocubes addition has not interfered with the barrier property of the coating but supplemented its corrosion protection behaviour.

The data have been curve-fitted using a parallel equivalent circuit with two time constants (figure 6), which is extensively used for such types of coatings. The obtained impedance parameters are shown in table 1 . The $R_{\text {ox }}$ for $1 \mathrm{~h}$ immersion condition is about $1.7 \times 10^{6} \Omega \mathrm{cm}^{2}$. The drop in the $R$ values is not very significant upon $168 \mathrm{~h}$ immersion for the sol-gel coating with ceria nanocubes, and the protection is superior when compared to coatings without $\mathrm{CeO}_{2}$ nanocubes (supplementary figure S2). These coatings are observed to be better than the coatings reported with ceria nanoparticles

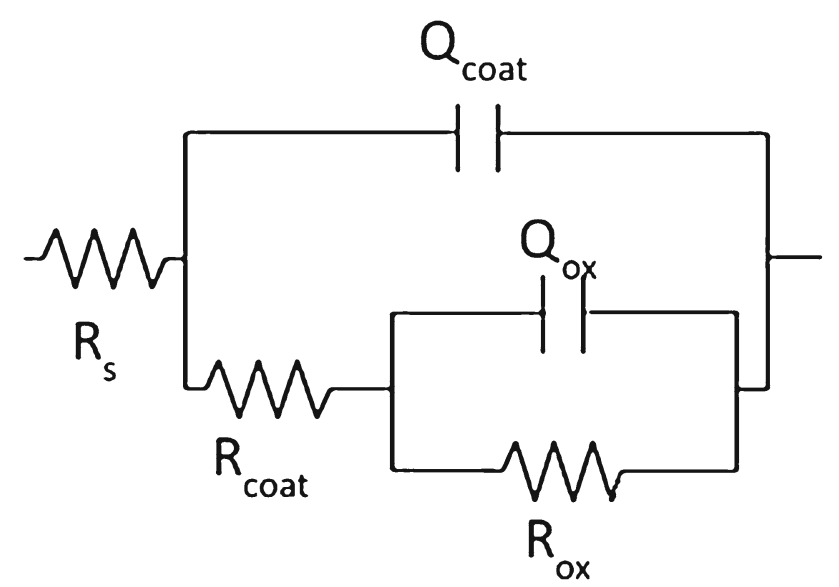

Figure 6. Electrical equivalent circuit used to fit the impedance data.

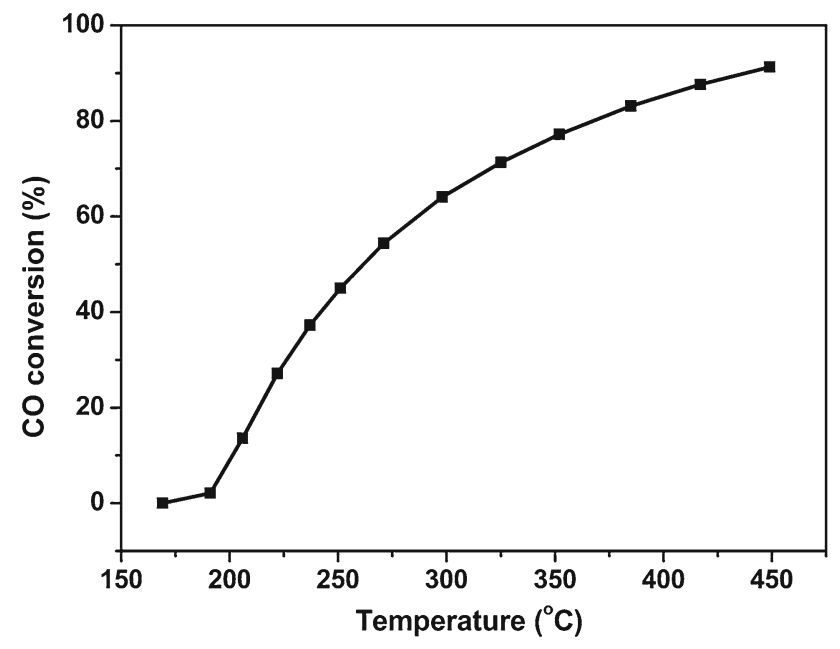

Figure 7. Plot showing $\mathrm{CO}$ conversion over $\mathrm{CeO}_{2}$ nanocubes.

under $1 \mathrm{~h}$ condition [43]. This may be due to the difference in the $\mathrm{Ce}^{3+}$ concentration in these two nanoparticles as determined by XPS. Further, although with much lower $\mathrm{CeO}_{2}$ content, the coatings with $\mathrm{CeO}_{2}$ nanocubes show an impedance value comparable with that reported by Wittmar et al [44]. This is because of the improved barrier nature of the coating and also the active corrosion protection offered by the $\mathrm{CeO}_{2}$ nanocubes.

\subsection{Catalytic properties}

$\mathrm{CO}$ oxidation has been carried out over $\mathrm{CeO}_{2}$ nanocubes, which is presented in figure $7 . \mathrm{CO}$ oxidation starts at $165^{\circ} \mathrm{C}$ and $50 \% \mathrm{CO}$ conversion occurs at $250^{\circ} \mathrm{C}$. Around $90 \% \mathrm{CO}$ conversion is observed at $450^{\circ} \mathrm{C}$. Chang and co-workers [45] have shown $15 \% \mathrm{CO}$ conversion at $300^{\circ} \mathrm{C}$ with hydrothermally synthesized $\mathrm{CeO}_{2}$ nanocubes having sizes in the range of $20-30 \mathrm{~nm}$ and a surface area of $35.9 \mathrm{~m}^{2} \mathrm{~g}^{-1}$. This catalytic activity difference can be due to the differences in the sizes of nanocubes. Current method of preparation yields $\mathrm{CeO}_{2}$ nanocubes with a size of $8-20 \mathrm{~nm}$, and consequently, it results in better catalytic activity towards $\mathrm{CO}$ oxidation, although it showed a surface area of $26 \mathrm{~m}^{2} \mathrm{~g}^{-1}$ (supplementary figure S3). A similar variation is noted in the work reported by $\mathrm{Wu}$ et al [46], with a particle size of $43 \mathrm{~nm}$ and a surface area of $29 \mathrm{~m}^{2} \mathrm{~g}^{-1}$. They have demonstrated $50 \% \mathrm{CO}$ conversion over $\mathrm{CeO}_{2}$ nanocubes towards $\mathrm{CO}$ oxidation and complete $\mathrm{CO}$

Table 1. Impedance parameters of ceria nanocube modified coatings at different immersion times.

\begin{tabular}{ccccccc}
\hline Time $(\mathrm{h})$ & $Q_{\text {coat }}\left(\mu \mathrm{S} \mathrm{s}^{\mathrm{n}} \mathrm{cm}^{-2}\right)$ & $n_{\text {coat }}$ & $R_{\text {coat }}\left(\Omega \mathrm{cm}^{2}\right)$ & $Q_{\text {ox }}\left(\mu \mathrm{S} \mathrm{s}^{\mathrm{n}} \mathrm{cm}^{-2}\right)$ & $n_{\text {ox }}$ & $R_{\mathrm{Ox}}\left(\mathrm{k} \Omega \mathrm{cm}^{2}\right)$ \\
\hline 1 & 0.55 & 0.84 & 29.72 & 3.11 & 0.94 & 1699 \\
168 & 1.58 & 0.63 & 251.8 & 4.02 & 0.9 & 390 \\
\hline
\end{tabular}


conversion was observed to occur above $500^{\circ} \mathrm{C}$. The turnover frequency of $\mathrm{CO}$ oxidation has also been calculated over $\mathrm{CeO}_{2}$ nanocubes from the flow rate, concentration of the active site and $\mathrm{CO}$ conversion below $10 \%$ at $200^{\circ} \mathrm{C}$ and it is found to be $0.625 \mathrm{~h}^{-1}$.

\section{Conclusions}

$\mathrm{CeO}_{2}$ nanocubes have been synthesized by a simple hydrothermal method. The size of the obtained ceria nanocubes with a cubic fluorite structure is about $8-20 \mathrm{~nm}$. The concentration of $\mathrm{Ce}^{3+}$ in the ceria nanocubes has been estimated by an XPS technique and is about $36 \%$ with respect to the total amount of Ce species. UV-Vis spectroscopy studies have demonstrated the presence of $\mathrm{Ce}^{4+}$ and $\mathrm{Ce}^{3+}$ species and the amount of $\mathrm{Ce}^{4+}$ is found to be high. Thermal studies show no major weight loss and reaction peaks, indicating that the product obtained has a negligible amount of hydrated water or unreacted residues. EIS studies on the AA2024-T3 substrate have shown that the addition of $\mathrm{CeO}_{2}$ nanocubes improves the corrosion inhibition properties of the AA2024-T3 substrate. CO oxidation is observed to occur at low temperature over $\mathrm{CeO}_{2}$ nanocubes, indicating its usefulness in exhaust catalysis.

\section{Acknowledgements}

We are grateful to the Director, CSIR-NAL and Chairman, Inorganic and Physical Chemistry Department, Indian Institute of Science, for their constant encouragement. Thanks to Head, SED for the unstinted support and encouragement. We thank Prof S Sampath, IISc, for the technical discussions. We also thank Mr Manikandanath, Mr Sreenivas, Mr Siju and Dr Parthasarathi Bera, for the thermal, XRD, FESEM and XPS studies, respectively. We also wish to thank Dr Arup Gayen, Jadavpur University, Kolkata, for catalysis experiment.

\section{References}

[1] Mai H X, Sun L D, Zhang Y W, Si R, Feng W, Zhang H P et al 2005 J. Phys. Chem. B 10924380

[2] Trovarelli A 2002 Catalysis by ceria and related materials (London: Imperial College Press)

[3] Bera P and Hegde M S 2015 RSC Adv. 594949

[4] Hegde M S and Bera P 2015 Catal. Today 25340

[5] Murugan B and Ramaswamy A V 2007 J. Am. Chem. Soc. 129 3062

[6] Kobayashi M and Flytzani-Stephanopoulos M 2002 Ind. Eng. Chem. Res. 413115

[7] Zhang Y W, Si R, Liao C S and Yan C H 2003 J. Phys. Chem. B 10710159

[8] Duan W D W, Xie A J, Shen Y H, Wang X F, Wang F, Zhang Y et al 2011 Ind. Eng. Chem. Res. 504441

[9] Lyons D M, Ryan K M and Morris M A 2002 J. Mater. Chem. 12 1207
[10] Zou H, Lin Y S, Rane N and He T 2004 Ind. Eng. Chem. Res. 433019

[11] Murray E P, Tsai T and Barnett S A 1999 Nature 400 649

[12] Suphantharida P and Osseo-Asare K 2004 J. Electrochem. Soc. $151 \mathrm{G} 658$

[13] Inaba H and Tagawa H 1996 Solid State Ionics 831

[14] Mohammadi M R and Fray D J 2010 Sens. Actuators B 150 631

[15] Kim W H, Maeng W J, Kim M K, Gatineau J and Kim H 2011 J. Electrochem. Soc. 158 G217

[16] Zhong X, Li Q, Hu J and Lu Y 2008 Corros. Sci. 502304

[17] Samide A and Tutunaru B 2011 Chem. Biochem. Eng. Quarterly 25203

[18] Shan W, Dong X, Ma N, Yao S, Feng Z and Soria J 2009 Catal. Lett. 131350

[19] Conesa J C, Martinez-Arias A and Fernandez-Garcia M 2000 Res. Chem. Intermed. 26103

[20] Ivanova A S 2009 Kinet. Catal. 50797

[21] Nolan M, Fearon J E and Watson G W 2006 Solid State Ionics 1773069

[22] Ahrens T J 1995 Global earth physics: a handbook of physical constants (Washington, D.C.: American Geophysical Union)

[23] Ganduglia-Pirovano M V, Hofmann A and Sauer J 2007 Surf. Sci. Rep. 62219

[24] Corradi A B, Bondioli F B, Ferrari A M and Manfredini T 2006 Mater. Res. Bull. 4138

[25] Kamruddin M, Ajikumar P K, Nithya R, Tyagi A K and Raj B 2004 Scr. Mater. 50417

[26] Si R, Zhang Y W, You L P and Yan C H 2005 Chem. Int. Ed. 443320

[27] Reed K, Cormack A, Kulkarni A, Mayton M, Sayle D, Klaessig F et al 2014 Environ. Sci. Nano 1390

[28] Taniguchi T, Watanabe T, Sakamoto N, Matsushita N and Yoshimura M M 2008 Cryst. Growth Des. 83725

[29] Wu N C, Shi E W, Zheng Y Q and Li W J 2002 J. Am. Ceram. Soc. 852462

[30] Fu X Q, Wang C, Yu H C, Wang Y G and Wang T H 2007 Nanotechnology 18145503

[31] Tang C C, Bando Y, Liu B D and Golberg D 2005 Adv. Mater. 173005

[32] Pahari S K, Sutradhar N, Sinhamahapatra A, Pala P and Panda A B 2011 New J. Chem. 351460

[33] Schem M, Schmidt T, Gerwann J, Wittmar M, Veith M, Thompson G E et al 2009 Corros. Sci. 512304

[34] Ershad-Langroudi A and Rahimi A 2014 Iran. Polym. J. 23 267

[35] Lakshmi R V, Aruna S T, Anandan C, Bera P and Sampath S 2017 Surf. Coat. Technol. 309363

[36] Anandan C and Bera P 2013 Appl. Surf. Sci. 283297

[37] Kubelka P and Munk F 1931 Z. Tech. Phys. 12593

[38] Tauc J, Grigorovic R and Vancu A 1966 Phys. Status Solidi 15 627

[39] Das D, Llorca J, Dominguez M, Colussi S, Trovarelli A and Gayen A 2015 Int. J. Hydrog. Energy 4010463

[40] Bera P and Anandan C 2014 Surf. Rev. Lett. 21 Art. no. 1450054

[41] Rao G R and Sahu H R 2001 Indian Acad. Sci. (Chem. Sci.) 113651

[42] Zhang F, Jin Q and Chan S W 2004 J. Appl. Phys. 95 4319 
[43] Lakshmi R V, Aruna S T and Sampath S 2017 Appl. Surf. Sci. 393397

[44] Wittmar A, Caparrotti H, Wittmar M and Veith M 2012 Surf. Interface Anal. 4470
[45] Chang S, Li M, Hua Q, Zhang L, Ma Y, Ye B et al 2012 J. Catal. 293195

[46] Wu Z, Li M and Overbury S H 2012 J. Catal. 285 61 